\title{
Lost in mobile? Exploring the mobile internet digital divide among Chinese college students
}

\author{
Lian Wang ${ }^{1}$ and Chun Liur $2^{*}$
}

\author{
*Correspondence: \\ chunliu@uestc.edu.cn \\ ${ }^{2}$ School of Public Affairs \\ and Administration, \\ University of Electronic \\ Science and Technology \\ of China, Chengdu, China \\ Full list of author information \\ is available at the end of the \\ article
}

\begin{abstract}
Mobile has become the primary mode of Internet access for many people. Existing studies have generally indicated that mobile Internet represents an inferior substitute for traditional PC-based Internet. In particularly, mobile-only users are often found to be the most disadvantaged. This paper explores the usage characteristics of multimodal users by differentiating mobile-reliant users, who primarily rely on mobile phones to access the Internet, and non-mobile-reliant users, who primarily use PCs to access the Internet, and investigates the socioeconomic characteristics of mobilereliant users, the association of the access preference and usage patterns, and whether a new type of digital divide has emerged. Based on data collected in a major public research university in southwest China, this study demonstrates that mobile-reliant users are not disadvantaged compared to non-mobile-reliant users in terms of usage, with the development of advanced mobile technology and the wealth of mobilefriendly content available therein. Practical implications for higher educators are also discussed.
\end{abstract}

Keywords: Internet usage, Digital divide, Mobile internet, Multimodal internet, College students

\section{Introduction}

The spread of mobile Internet far outpaces that of fixed PC-based Internet access. According to China Internet Network Information Center (CNNIC), as of December 2020, China had 989 million Internet users and the Internet penetration had reached 70.4\%. In 2020, $99.7 \%$ of China's Internet users (986 million) accessed the Internet via their mobile phones while $32.8 \%$ and $28.2 \%$ of them accessed the Internet via desktop and laptop respectively ${ }^{1,2}$ (CNNIC 2021). The popularity of mobile technology is

\footnotetext{
${ }^{1}$ According to the CNNIC, Internet users are defined as the Chinese residents at the age of 6 or above who have used the Internet in the past 6 months and mobile (desktop, laptop computers) Internet users are defined as Internet users who have used mobile phones (desktop, laptop computers) to access and surf the Internet in the past 6 months, but not limited to those surfing the Internet via mobile phones (desktop, laptop computers) only.

2 Please refer to the CNNIC's annual Statistical Report on Internet Development in China for the detailed demographic and socioeconomic characteristics of China's Internet users. The latest English version report can be found at http:// cnnic.com.cn/IDR/ReportDownloads/202012/P020201201530023411644.pdf.
} source, provide a link to the Creative Commons licence, and indicate if changes were made. The images or other third party material in this article are included in the article's Creative Commons licence, unless indicated otherwise in a credit line to the material. If material is not included in the article's Creative Commons licence and your intended use is not permitted by statutory regulation or exceeds the permitted use, you will need to obtain permission directly from the copyright holder. To view a copy of this licence, visit http://creativecommons. org/licenses/by/4.0/. 
beneficial for traditionally disadvantaged groups as it provides them with a comparatively cheap and less technologically sophisticated access to the Internet. However, It is argued that mobile Internet represents an inferior form of Internet access in many aspects, such as "content availability, platform and network openness, speed, memory, and interface functionality among other things" (Napoli and Obar, 2014, p. 330).

For college students, Internet is part of the daily routine to connect with others, access educational and other resources, and entertain. Studies on the college students' Internet usage in China have generally focused on the prevalence of Internet addiction and the possible factors related to this phenomena (Chi et al. 2016; Huang et al. 2009; Ni et al. 2009). Mobile technology has become a life necessity for college students in recent years (Chen and Katz 2009). It is found that after controlling for other established predictors, increased cell phone use negatively impacts academic performance, measured by GPA (Felisoni and Godoi 2018; Hawi and Samaha 2016; Lepp et al. 2014, 2015; Seo et al. 2016). College students are more likely to sacrifice academic work, rather than time for social media, smart phones, or leisure activities, in cases of a lack of time (Janković et al. 2016). In general, digital divide scholars have found that people, particularly those with lower socioeconomic status, are more likely to depend on a smartphone for Internet access and to use the Internet for non-capital-enhancing activities (Humphreys et al. 2013; Jung 2008; Kongaut and Bohlin 2016; Kreutzer 2009; Mossberger et al. 2012; Napoli and Obar 2014; Pearce and Rice 2013). However, prior studies have not fully discovered how college students use their mobile Internet. In particularly, little is known on the impact of students' socioeconomic status on their preference for an Internet access method and how the increasing dependence on mobile technology may impact students' Internet usage behavior.

\section{Literature review}

There is a growing body of research studying the patterns of Internet use determined by the technological characteristics of different access technologies. Overall, existing studies have suggested that the technological limitations of the mobile devices prevent more intensive content creation, user engagement and capital-enhancing activities (Mossberger et al. 2012; Napoli and Obar 2014).

In terms of user characteristics, since the mobile technology provides a comparatively cheap and less technologically sophisticated access to the Internet, the traditionally unrepresented groups in terms of fixed Internet access have adopted mobile communication devices at rates equal to or faster than those observed in the base population (Wareham et al. 2004). Compared to PC Internet access, mobile Internet access seems to be less affected by demographics, socioeconomic status, and technological readiness (Akiyoshi and Ono 2008). Existing studies in developed countries have generally found that the mobile-only population is more likely to comprise traditionally disadvantaged groups (Lee and Kim, 2014; Mossberger et al. 2012; Tsetsi and Rains 2017).

Comparing mobile and PC-based Internet usage, it is found that people tend to use personal computers for a broader spectrum of activities (Jung 2008). PC-based Internet usage is immersive, whereas mobile Internet usage is extractive (Humphreys et al. 2013). In the young generations who are said to be mobile-natives, it is found that they tend to use their mobile phones for recreation and entertainment purposes, especially playing 
games and listening to music, and are less likely to use them for more sophisticated purposes, such as petitioning, voting, or shopping (Kreutzer 2009; Lin et al. 2013).

It is argued that the skill and usage gaps may have widened among mobile-only users. This group of users not only lacks alternative Internet access but also is likely to use mobile Internet less frequently and in an ineffective way. Mobile-only users often have difficulties in maintaining the services, finding mobile-friendly content online and using the mobile Internet effectively with the limited functionality of their mobile device (Donner et al. 2011; Gitau et al. 2010). Multimodal connectedness (the number of communication technologies used for social interactions) enhances well-being for older-age cohorts (35+) (Cha 2015). Comparing to PC-based or multimodal users, mobile-only users do not only access the Internet less frequently, but also use it more for non-capital-enhancing activities (Pearce and Rice 2013). For example, mobileonly users are more likely to use music, video, and social networking applications, but less for political and economic activities (Kongaut and Bohlin 2016; Mossberger et al. 2012). However, as mobile technology advances, it is possible that the device divide in usage has to some extent narrowed. For instance, based on an analysis of operational data from a major Chinese telecommunications carrier, mobile-only users actually exhibit a greater variety of mobile Internet usage than multimodal counterparts (Wang and Liu 2018). Since mobile applications have become increasingly "task-supportive", some users may prefer smartphones for activities previously possible only on PCs (Donne 2015).

Interestingly, while there is a conventional assumption that some Internet activities can be capital-enhancing and improve one's life prospects, no well-defined classification exists in the previous digital inequality literature (Pearce and Rice 2013; van Deursen and van Dijk 2014; Zillien and Hargittai 2009). Blank and Groselj (2014) review previous studies and find that existing typologies are inconsistent, rigid, and primarily datadriven, with few theoretical guidelines. Typically, health and government interactions, personal development, and news and information are usually considered to be "capitalenhancing" activities. In a recent multinational research project, it is suggested that Internet usage can be categorized into four fields: economic, cultural, social and personal (Helsper et al. 2016). Overall, there lacks a consensus on the theory-based Internet usage classification.

In summary, most, if not all, existing studies have focused on the different usage pattern corresponding with specific access technologies and have often emphasized the mobile-only population. While these studies have contributed new insights to digital divide studies, they seemingly assume that multimodal users are homogeneous, and there is a dearth of research on the Internet usage of this population. This study further differentiates multimodal users into mobile-reliant users, who primarily rely on mobile phones to access the Internet, and non-mobile-reliant users, who primarily use PCs or both to access the Internet, and compares the two groups' overall Internet usage. This article contributes to the existing research on the mobile digital divide by investigating the characteristics of mobile-reliant users, the association of the access preference and usage patterns, and whether it has created another layer to the digital divide.

This study aims to explore the following two research questions.

RQ1. Are traditionally low socioeconomic groups more likely to be mobile-reliant? 
RQ2. How do mobile-reliant and non-mobile-reliant groups use the Internet differently?

\section{Methods}

\section{Sample}

Data were collected from a major public research university in southwest China between March 1 and March 20, 2017. The participants were sophomore, junior and senior students. The questionnaire was distributed by a research team member personally at the end of class to ensure a high response rate (85\%) as well as to avoid any misunderstanding in the process of responding. There were 445 responses. Respondents generally took 10-15 min to finish the survey. The participants were awarded a notebook as a gift for finishing the survey questionnaire. Since convenience sampling was used in this study, caution should be exercised when the findings are generalized to other populations.

\section{Survey development and measurements}

The questionnaire design benefited mainly from two earlier survey studies. The first is the "From digital skills to tangible outcomes (DiSTO)" project (van Deursen et al. 2016), and the second is the Oxford Internet Surveys. The original questionnaire was translated, refined, and culturally modified to the Chinese version by a panel of three scholars. The questionnaire contained the operational measures of device access, Internet skills, type of use, and sociodemographic.

\section{Device access}

Respondents were asked the following question: "Overall, when you go online, do you mostly use your mobile phone or mostly use some other device such as a desktop, laptop or tablet computer?"; they were given the choice of "mostly use my mobile phone", "mostly use my computer" and "both equally". The responses were recoded to create the device access variable. Mobile-reliant users who reported mostly using mobile phones to access the Internet were coded as 1 , and the respondents who reported mostly using a computer or both equally in the form of Internet access were coded as 0 .

\section{Internet skills}

Respondents were asked how confident they feel performing various tasks in an online environment on a 5-point scale. The sample items for Internet skills include "judge the reliability of online content", "remove a virus that infected your computer", "participate in a discussion online", "make new friends online", "upload photos to a website" and "download and save music". Consequently, the average of the 6 items was used as a measure of Internet skills $(\alpha=0.74)$.

\section{Demographic and socioeconomic characteristics}

We included relevant demographic and socioeconomic variables in our analysis. Gender was included as a dichotomous variable. Male respondents coded as 0 and female respondents coded as 1 . Although age was a common demographic variable included in the questionnaire, it was not included in the analysis because of the lack of variance in our sample $(M=20.3, S D=1.1)$. 
We asked the respondents to report the education of their parents. Studies in higher education have generally concluded that first-generation college students were more likely to come from a lower socioeconomic background and first-generation students suffer from a cumulative disadvantage (Bui 2002; Pascarella et al. 2004). The responses ranged from "none" to "master's degree or above". The respondents who reported a bachelor's degree or higher level of education for either parent were coded as 0 , and those who reported an education level lower than a bachelor's degree for both parents were classified as "first-generation college students" (FGCS) and coded as 1.

As urban-rural dual structure in the context of China remains the most important analytical framework for a digital divide study (Guo and Chen 2011), we asked the respondents whether their place of residence was located in an urban or a rural area.

In addition, a student's monthly allowance is used to reflect his/her family income, which is an important predictor of differences in communications technology ownership and use (Junco et al. 2010). Research has shown that students from low-income families may have primarily dealt with simpler communication and presentation technologies and that such students act as consumers, instead of creators, of online content (Greenhow et al. 2009). Respondents reported their average allowance per month during the last year in one of 3 categories ranging from less than $¥ 1000$ to more than $¥ 1500$.

\section{Internet usage}

Internet usage is defined in terms of use duration and the type of activities performed. All the respondents were asked how many hours they spent online at school and at home during summer/winter breaks.

For types of use, the respondents were asked a series of questions about how often they engage in different types of Internet usage on a 6-point scale, ranging from never to several times a day (See Appendix 1 for different items used to evaluate types of Internet usage activities).

First, the respondents were asked about their general Internet usage, including instant messaging, emails, social media networking, blogging, watching videos and gaming. The items were subjected to exploratory factor analysis, which identified three factors, namely, common usage, self-actualization, and leisure activities. Consequently, 4 items were averaged as a measure of general use $(\alpha=0.58), 4$ items were averaged as a measure of self-actualization $(\alpha=0.62)$ and 3 items were averaged as a measure of leisure activities $(\alpha=0.66)$.

The respondents were then asked about three specific types of Internet usage activities: information activities, economic activities and social activities.

\section{Information activity}

This measure was created using 12 items that captured the extent to which the Internet was used to acquire different types of information. For the sake of parsimony, all correlating dimensions were subjected to exploratory factor analysis, which identified three factors, namely, generic information seeking, specific information seeking, and capital-enhancing information seeking. Consequently, 5 items were averaged as a measure of generic information seeking $(\alpha=0.77), 4$ items were averaged as a measure of 
specific information seeking $(\alpha=0.66)$ and 3 items were averaged as a measure of capital-enhancing information seeking $(\alpha=0.58)$.

\section{Economic activity}

The economic category was divided into education and property. The measure for the education subcategory was created by averaging 7 items that captured the extent to which the Internet was used to gain knowledge $(\alpha=0.77)$. The measure for the property subcategory was created by averaging 9 items that captured the extent to which the Internet was used to buy and sell things $(\alpha=0.66)$.

\section{Social activity}

This measure was created using 13 items that describe Internet usage associated with bonding and networks on social media online platforms. Exploratory factor analysis identified three factors, namely, following feeds, engaging with others and creating content. Consequently, 4 items were averaged as a measure of following feeds $(\alpha=0.68), 4$ items were averaged as a measure of engaging with others $(\alpha=0.72)$ and 5 items were averaged as a measure of creating content $(\alpha=0.82)$.

\section{Data analysis}

To quantify the effects of the sociodemographic factors on mobile dependency, we conducted a logistic regression analysis. We conducted two analyses to answer whether mobile-reliant and non-mobile-reliant groups use the Internet differently and to identify the predictors of different types of Internet activities. First, the differences in the types of Internet activities were compared using t-tests. Second, we carried out multiple regression analyses to identify the predictors of different types of Internet activities. All sociodemographic variables as well as the mobile dependency variable were entered in the regression model with activities serving as the outcome variables.

\section{Results}

\section{Descriptive statistics}

The summary statistics of the key variables are provided in Table 1, which shows that mobile-reliant users accounted for $66 \%$ of our sample. Female users accounted for a proportionally larger share than male users ( $58 \%$ versus $42 \%$ ). $69 \%$ of the respondents were first-generation college students. Rural users made up more than a half of the sample (55\%). $13 \%$ of the respondents lived on monthly allowance less than $¥ 1000$, and $38 \%$ of the respondents lived on monthly allowance over $¥ 1500$.

It was found that male college students had a higher level of Internet skills $(M=2.50)$ than their female counterparts $(M=2.36)$. College students from urban areas had a higher level of Internet skills $(M=2.52)$ than college students from rural areas $(M=2.34)$. First-generation college students had a lower level of Internet skills $(\mathrm{M}=2.37)$ than non-FGCS $(\mathrm{M}=2.53)$. Independent $\mathrm{t}$-tests revealed that the differences were all statistically significant at 0.01 level. 
Table 1 Summary statistics

\begin{tabular}{|c|c|c|c|}
\hline & Variable & Mean & SD \\
\hline Device access & Internet access ( $1=$ mobile-reliant; $0=$ non-mobile-reliant $)$ & 0.66 & 0.48 \\
\hline \multirow[t]{4}{*}{ Sociodemographic } & Gender ( 1 = female; $0=$ male) & 0.58 & 0.49 \\
\hline & FGCS ( $1=$ first-generation college students; $0=$ Non-FGCS) & 0.69 & 0.46 \\
\hline & Residence $(1=$ urban; $0=$ rural $)$ & 0.45 & 0.50 \\
\hline & Allowance $(1=$ low; $2=$ middle; $3=$ high $)$ & 2.25 & 0.67 \\
\hline Internet skills & Skill & 2.42 & 0.62 \\
\hline \multirow[t]{2}{*}{ Internet use duration } & Duration at school & 5.17 & 2.67 \\
\hline & Duration at home during school breaks & 6.71 & 3.21 \\
\hline \multirow[t]{11}{*}{ Types of Internet usage } & Common usage & 4.02 & 0.72 \\
\hline & Self-actualization & 1.91 & 0.96 \\
\hline & Leisure & 2.31 & 1.33 \\
\hline & Generic information & 2.75 & 1.00 \\
\hline & Specific information & 3.08 & 0.98 \\
\hline & Capital-enhancing information & 1.56 & 0.86 \\
\hline & Education & 3.23 & 0.77 \\
\hline & Property & 2.59 & 0.61 \\
\hline & Following Feeds & 3.36 & 0.97 \\
\hline & Engaging with others & 1.32 & 0.87 \\
\hline & Creating content & 2.40 & 1.01 \\
\hline
\end{tabular}

Table 2 Logistic regression analysis on mobile dependency

\begin{tabular}{llc}
\hline & Odds ratio & Standard error \\
\hline Gender & $7.90^{* * *}$ & 1.88 \\
Residence & 0.78 & 0.19 \\
FGCS & $2.07^{* *}$ & 0.56 \\
Allowance & & \\
2.allowance & 1.36 & 0.47 \\
3.allowance & 0.91 & 0.33 \\
CONSTANT & $0.42^{*}$ & 0.17 \\
Likelihood Ratio & $98.27^{* * *}$ & \\
McFadden's pseudo R2 & 0.17 & \\
$\mathrm{~N}$ & 445 & \\
\hline Gender: male is used as the reference group; FGCS: non-FGCS is used as the reference group. Allowance: Allowance of less \\
than $¥ 1000$ is used as the reference group & & \\
${ }^{*} \mathrm{p}<0.05,{ }^{* *} \mathrm{p}<0.01$, and ${ }^{* * *} \mathrm{p}<0.001$ & &
\end{tabular}

\section{Socioeconomic indicators and device access (RQ 1)}

As shown in Table 2, the results confirmed that gender and FGCS each played a significant role in determining the likelihood of being mobile-reliant, whereas place of residence and allowance did not have a significant effect on mobile dependency. The odds ratio indicated that the likelihood of being mobile-reliant for women was 7.90 times more than the corresponding likelihood for men. Similarly, for first-generation college students, the likelihood of being mobile-reliant was 2.07 times more than the corresponding likelihood for students whose parents have a bachelor's degree or higher. 
Table 3 Differences in means of key variables by device access

\begin{tabular}{|c|c|c|c|c|c|}
\hline & & Mobile-reliant & $\begin{array}{l}\text { Non- } \\
\text { mobile- } \\
\text { reliant }\end{array}$ & $\begin{array}{l}\text { Test Statistic } \\
\text { (t/chi-square) }\end{array}$ & $P$ value \\
\hline \multirow[t]{4}{*}{ Sociodemographic } & Gender & 0.73 & 0.29 & 79.00 & $<0.001$ \\
\hline & Parents'education & 0.73 & 0.61 & 7.34 & $<0.01$ \\
\hline & Residence & 0.42 & 0.51 & 3.43 & 0.06 \\
\hline & Allowance & 2.23 & 2.28 & 2.74 & 0.25 \\
\hline Internet skill & Skill & 2.40 & 2.46 & 1.04 & 0.30 \\
\hline \multirow[t]{2}{*}{ Internet duration } & Duration at school & 5.22 & 5.07 & -0.54 & 0.59 \\
\hline & $\begin{array}{l}\text { Duration at home during } \\
\text { school breaks }\end{array}$ & 6.76 & 6.60 & -0.47 & 0.64 \\
\hline \multirow[t]{3}{*}{ General Internet usage } & Common usage & 4.05 & 3.97 & -1.18 & 0.23 \\
\hline & Self-actualization & 1.99 & 1.74 & -2.60 & $<0.01$ \\
\hline & Leisure & 2.06 & 2.77 & 5.49 & $<0.001$ \\
\hline \multirow[t]{3}{*}{ Information activity } & Generic information & 2.69 & 2.86 & 1.70 & 0.09 \\
\hline & Specific information & 3.17 & 2.9 & -2.72 & $<0.01$ \\
\hline & Capital-enhancing information & 1.64 & 1.42 & -2.64 & $<0.01$ \\
\hline \multirow[t]{2}{*}{ Economic activity } & Education & 3.18 & 3.31 & 1.68 & 0.09 \\
\hline & Property & 2.60 & 2.56 & -0.70 & 0.48 \\
\hline \multirow[t]{3}{*}{ Social activity } & Following Feeds & 3.40 & 3.29 & -1.13 & 0.26 \\
\hline & Engaging with others & 1.38 & 1.23 & -1.74 & 0.08 \\
\hline & Creating content & 2.49 & 2.23 & -2.57 & 0.01 \\
\hline
\end{tabular}

\section{Differences in internet usage between mobile-reliant and non-mobile-reliant students (RQ 2)}

The results of t-tests on the differences in the types of Internet activities are reported in Table 3. For the types of personal activity, the mobile-reliant group engaged in significantly more self-actualization activities than the non-mobile-reliant group. This pattern was reversed for leisure activities: the mobile-reliant group engaged in leisure activities significantly less frequently than their non-mobile-reliant counterparts. General use in the subcategory of personal activity was not significantly different for the two groups. For the types of Information activity, the mobile-reliant group used the Internet significantly more frequently for both specific information seeking and capital-enhancing information seeking activities than the non-mobile-reliant group. The two groups did not show a significant difference in generic information seeking activities. Regarding economic activity, there was no significant difference in either the education or property subcategory activities between the mobile-reliant group and the non-mobile-reliant group. For the social activity, the mobile-reliant group was significantly more active in engaging with others and creating content than the non-mobile-reliant group. Following feeds in the subcategory of social activity was not significantly different for the two groups.

The regression results are presented in Table 4. Gender was a significant predictor of most of the activities. Compared to men, women were significantly more active in the fields of general use and self-actualization of personal activity and significantly less active in the field of leisure of personal activity. Regarding Information activity, women engaged significantly less in generic information seeking and more in specific information seeking. Men and women also differed significantly in social activity in that women were more likely to perform following feeds and less likely than men to engage with others. 


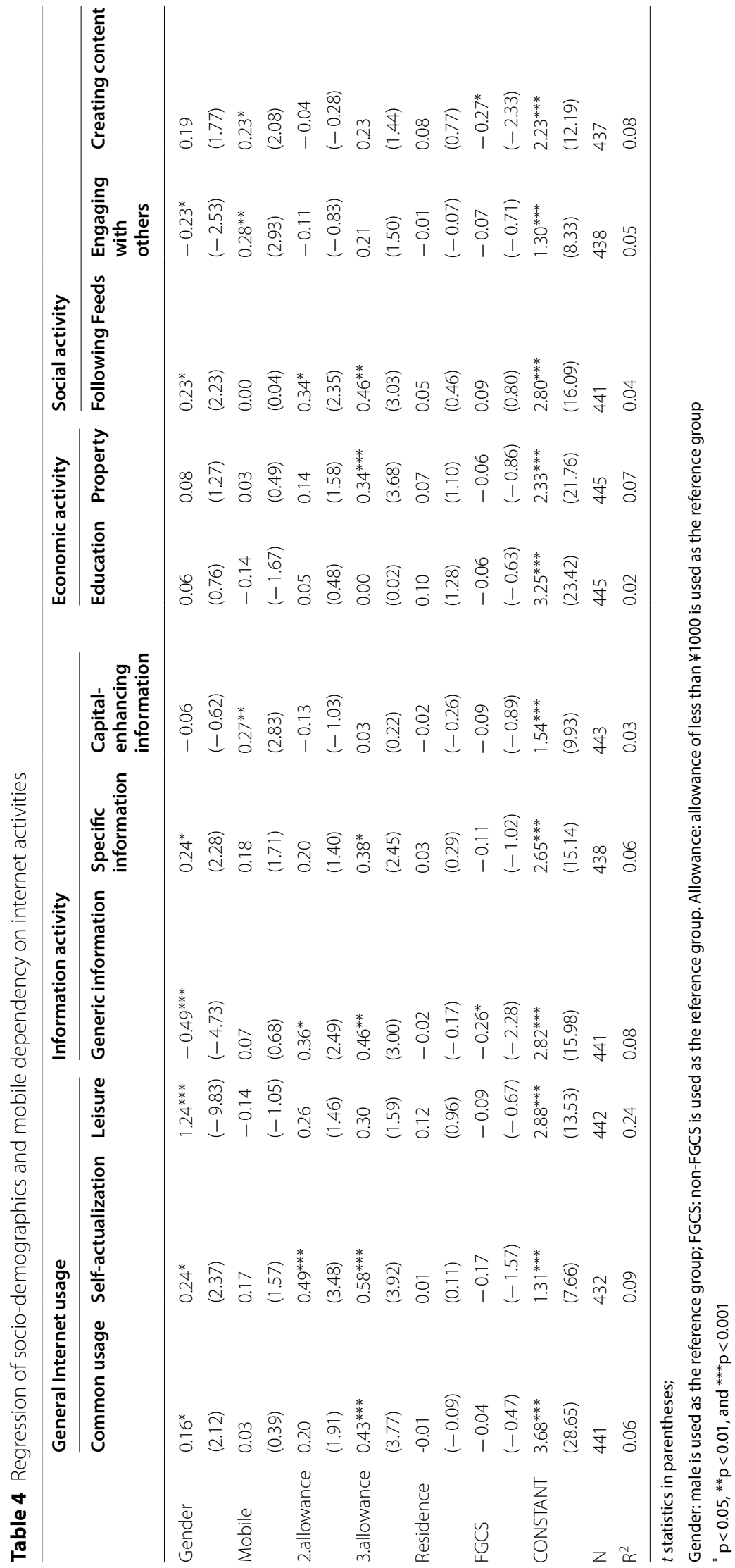


Allowance significantly predicted self-actualization of general Internet usage, generic information seeking, property of economic activity and following feeds of social activity. Compared to students with allowances less than $¥ 1000$ a month, respondents with allowances more than $¥ 1500$ a month were significantly more engaged in these activities.

Parents' education was a significant predictor for browsing generic information activity and creating content on social activity. Compared to respondents whose parents had bachelor's degrees or higher, first-generation college students engaged significantly less frequently in browsing generic information and creating content while interacting with others on the Internet. The place of residence was not a significant predictor for any activity.

After controlling for the effects of sociodemographic factors, mobile dependency showed significant predictive power in capital enhancing of Information activity as well as two subcategories of social activity. When engaging in information activity, mobilereliant Internet users were significantly more likely than non-mobile-reliant Internet users to perform capital-enhancing activities, such as making travel plans, looking for jobs and finding information about health. When engaging in social activity online, mobile-reliant Internet users engaged with others and created content significantly more frequently than non-mobile-reliant Internet users.

\section{Discussion}

In our sample, all the students used mobile phones to access the Internet, and nearly two-thirds $(65.8 \%)$ of them declared that the mobile phone was their primary means of Internet access. It is evident that the young generation has largely shifted their Internet usage to the mobile platform. Thus, it is pertinent to investigate whether mobile phones provide an adequate alternative to traditional PC-based Internet access.

\section{Device access}

The result of this study shows that some traditional determinants of the digital divide no longer apply to the young generation. There is no significant difference in either place of residence or students' monthly allowance in terms of students' platform preference.

However, intriguingly, the likelihood of being mobile-reliant for women was 7.90 times more than the corresponding likelihood for men. Studies based on data from the U.S. have generally concluded that gender was unrelated to how individuals access the Internet and that the gender divide was actually reversed in favor of females after 2001 (Campos-Castillo 2015; Talukdar and Gauri 2011). However, a recent meta-analysis revealed that females still exhibit less positive attitudes toward technology use (Cai et al. 2017). In particular, Chinese women were found to be more strongly influenced by their computer attitudes in technology adoption, implying that the usefulness of a technology is a salient determinant of Chinese users' acceptance of it, especially for females (Dong and Zhang 2011). In addition, existing studies have generally failed to reach a consensus regarding the relationship between gender and ICT competence (Talukdar and Gauri 2011). In our sample, there was a significant difference between males and females regarding the Internet skills reported. Overall, male students reported higher Internet skills than female students. Thus, the easier-to-use feature of mobile Internet access might be more appealing to females than to males and result in a higher level of mobile dependency. Another possible explanation for gender difference is that males might engage in more 
gaming that requires the support of PC. As one of the items used to measure leisure activities "Play a game on the computer" indicates, male college students use PC to play games more frequently $(M=3.21)$ than their female counterparts $(M=1.34)$.

Moreover, in our data, first-generation college students were significantly more likely to be mobile-reliant than their counterparts. Since other socioeconomic indicators, such as household income and occupations, cannot be accurately measured in the student sample, parents' educational level provides an adequate proxy reflecting the socioeconomic status of a student's family. To some extent, our data support the optimistic view that some of the traditionally underrepresented groups might adopt mobile Internet at faster rates and that smartphones appear to be leveling the playing field (Tsetsi and Rains 2017; Wareham et al. 2004). On the other hand, the higher dependency rate also raises the concern that there exists a continued device divide between key socioeconomic groups. As argued by Tsetsi and Rains (2017), people from traditionally disadvantaged groups often rely on fewer and more limited devices to access the Internet.

\section{Internet usage}

Some previous studies have found that those with higher socioeconomic status are more likely to use the Internet to search for capital-enhancing information activities and that such differentiated usage of the Internet not only reflected but also contributed to existing societal inequalities (van Deursen et al. 2015; Witte and Mannon 2010; Zillien and Hargittai 2009). In particularly, evidence from a U.S. university shows that socioeconomic status is an important predictor of Internet usage and students with a lower socioeconomic status exhibit lower levels of Web know-how and tend to engage in fewer information-seeking activities online on a regular basis than others (Hargittai 2010). Students from households with a higher income status tend to use full-spectrum technology more frequently (Ching et al. 2005; Livingstone and Helsper 2007).

We argue that the capital-enhancing and non-capital-enhancing dichotomy should be applied with caution because of the multipurpose nature of many Internet activities. There is no clear dividing line between good and bad in a specific usage type. Considering this fact, it is reasonable to assume that some Internet activities are more capitalenhancing than others, as suggested by Pearce and Rice (2013). In our study, exploratory factor analysis was conducted to investigate Internet usage patterns. Intuitively, the components identified in the analysis seem to reflect the extent to which a group of Internet activities are capital-enhancing. In addition, there is a clear pattern showing that capital-enhancing activities are usually more technologically sophisticated and require more user involvement.

Nevertheless, our analysis revealed that demographic and socioeconomic factors are still associated with different types of Internet usage among college students. Gender was a significant predictor of most of the activities. However, contrary to the traditional view of females as a disadvantaged group, female students in our sample were actually more active in capital-enhancing, self-actualization activities and less so in leisure activities. Similarly, when looking up information online, females were found to be significantly more proactive than males. In terms of socioeconomic status, students with higher monthly living allowances were more active with respect to most Internet activities. 
Overall, controlling for other sociodemographic factors, the difference between the mobile-reliant group and its counterpart in terms of Internet usage is minor. The differences are insignificant in most usage categories. We found little evidence in support of the mobile underclass argument. In contrast, the mobile-reliant group engaged in significantly more self-actualization activities and less leisure activities than the non-mobilereliant group. The mobile-reliant group used the Internet more frequently to search for information both to look up specific information and to search for capital-enhancing information activities. In addition, the mobile-reliant group was significantly more active in engaging with others and creating content. In our sample, mobile-reliant users compared equally, if not more favorably, to non-mobile-reliant users in terms of engaging in "capital-enhancing" Internet activities. This result is consistent with the findings of Wang and Liu (2018), who did not find sufficient evidence to support the notion of the "mobile underclass" based on an analysis of operational data from a major Chinese telecommunications carrier.

Previous studies have proposed two explanations for the possible emergence of a mobile underclass. First, the mobile-reliant population is more likely to be comprised of traditionally disadvantaged groups, which tend to use mobile devices less effectively because of the divide between low and high socioeconomic groups in terms of the required innovativeness and competence for using mobile technology efficaciously (Lee and Kim 2014; Mossberger et al. 2012; Tsetsi and Rains 2017). However, in our study, as in Pearce and Rice's (2013) Armenia-based study, it appears that both sociodemographic factors and levels of mobile-dependency influence usage, although demographics matter more in most of the usage categories. Second, the limitation of mobile technology may also contribute to the creation of a mobile Internet underclass (Napoli and Obar 2014). We argue that this technological deterministic view is now largely obsolete with the rapid development of mobile technology in recent years. Certainly, there may still exist a performance divide between mobile devices and personal computers. However, smartphones can now handle most daily at-home and even some at-work tasks in a more convenient way.

\section{Conclusions and limitations}

The findings of this study offer an updated and fuller viewpoint of the digital divide regarding the mobile Internet. At its emergence, mobile Internet was considered an extension of PC-based Internet usage (Nielsen and Fjuk 2010). With the mobile ecosystem reaching maturity, recent studies have provided convincingly strong evidence for fixed-mobile substitution on both access and traffic levels (Barth and Heimeshoff 2014). Apparently, mobile communication has changed from a supplemental technology to a substitutive one. It is reasonable to speculate that the PC might have become an extension of mobile for complicated tasks that cannot be easily performed on mobile, particularly for the young generation. Previous PC-based Internet usage studies have suggested that the differentiated usage of the Internet not only increasingly reflects the use of traditional media and known offline economic, social, and cultural relationships, including inequalities but also contributes to the reproduction of such inequalities (van Deursen et al. 2015; Witte and Mannon 2010; Zillien and Hargittai 2009). Although a divide still remains in terms of technological capacity between 
mobile and PC, this study has demonstrated that with regard to usage, mobile-reliant users are not disadvantaged compared to non-mobile-reliant users. The concern of the mobile underclass, raised by some digital divide scholars, has been gradually diminishing with the development of advanced mobile technology and the wealth of content available therein.

This research has important practical implications, particularly for higher education administrators. Despite the concern that college students' cell phone use is negatively associated with academic performance as well as mental and physical health, higher education administrators and faculties must accept the fact the mobile has become the preferential method of Internet access for college students. In practice, instead of attempting to limit college students' cell phone use, efforts should be made to take full advantage of this technology. For example, higher education institutions shall migrate PC-based learning platforms to mobile-based ones and develop mobilefriendly educational resources. In particularly, mobile technology benefit traditionally disadvantaged groups to a greater extent, as these groups tend to more quickly embrace new technology and skip the PC stage because of greater affordability and the relatively lower learning curve associated with these new technologies. To some extent, as college students with lower socioeconomic status are more likely to rely on mobile phones, the development of mobile-based instructional applications might be a more cost-effective way of leveling the playing field for them.

As with most empirical work, the present study is not without limitations. First, the potential generalizability of this study is limited by the characteristics of the study participants. College students are generally younger and more educated than the national average. Usage patterns might therefore be different among other sociodemographic groups. Second, in terms of measurement, previous studies have found out, while the actual time and application type patterns of measured data roughly match the self-report data, some users, such as those who are self-conscious, might underestimate their actual mobile Internet usage, and certain compulsive use cannot be captured by self-report data (Lee et al. 2017; Wilcockson et al. 2018). Third, the effects of the popular big-data-based personalized information/APP recommendation system on Internet usage requires further investigation. Studies of the current design of Internet usage do not distinguish whether a specific Internet activity is triggered by a user's self-judgement, the recommendations of the operating system, or an APP. If mobile users are constrained by personalized recommendations, they may be exposed to narrower perspectives, which might in turn create another level to the digital divide. Forth, while this study has found little evidence in support of the mobile underclass argument in terms of college students' Internet usage, we cannot completely understand why mobile-reliant groups actually engaged more actively in some capital-enhancing Internet activities than non-mobile-reliant groups, which warrants future investigation. 


\section{Appendix 1}

\section{See Table 5.}

Table 5 Items used to evaluate types of Internet usage activities

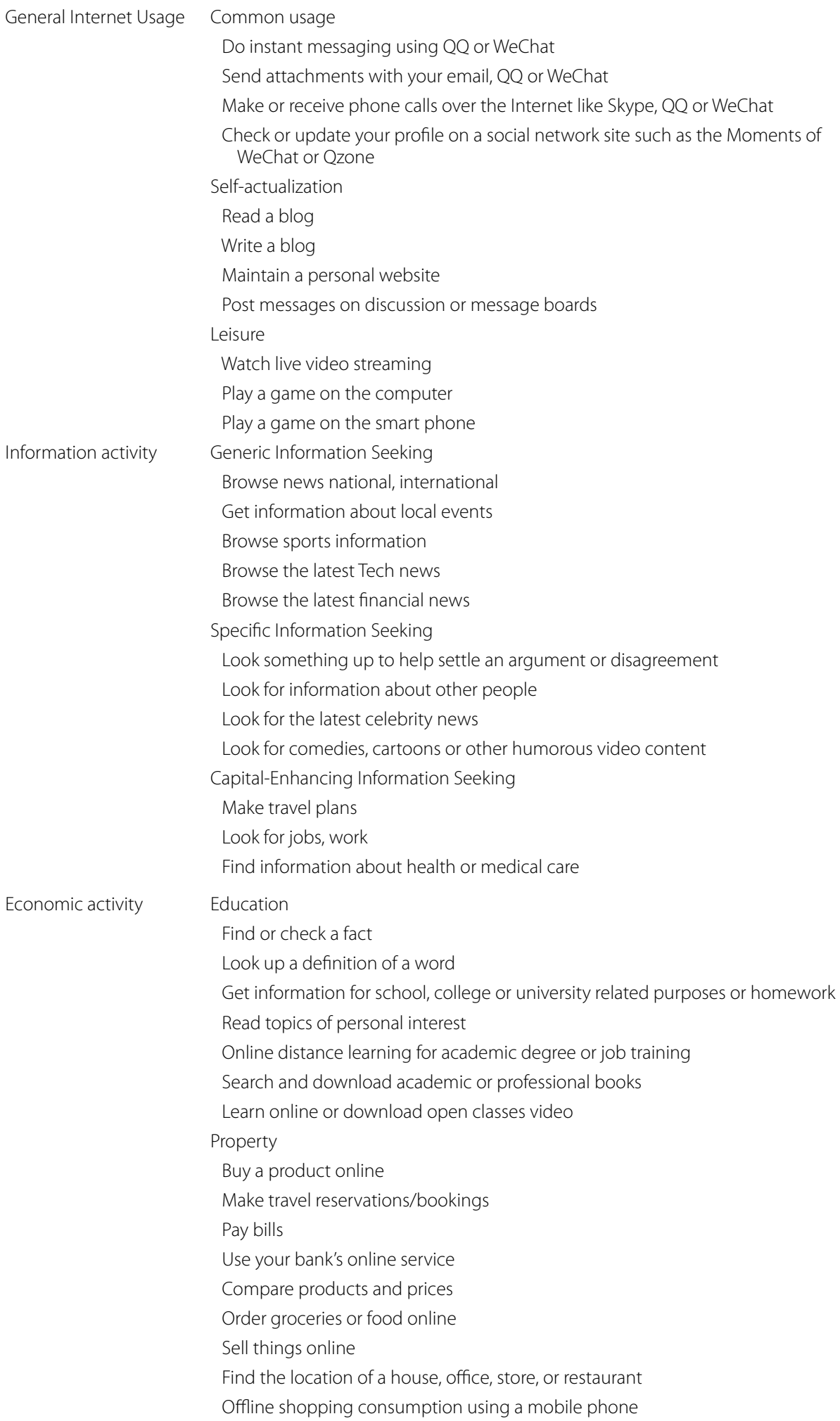


Table 5 (continued)

Sollowing feeds
Click through links on social network
Read news or other information on social network
Follow Official Accounts on WeChat
"Like" the content in the Moments of other people
Engaging with others
Update personal information on social networks
Check or change privacy settings of the Moments of WeChat
Participate in discussing political issues
Un-follow or drop someone from your network
Creating content
Update your status on social networks such as the Moments of WeChat
Post pictures on social networks
Post your writing, stories or any other creative content on social networks
Add comments on others' posts on social networks
Re-post and share links, news, videos, or any creative content originally posted by
others

\section{Acknowledgements}

Zhang, Ruokun of Hubei University of Education contributed to the questionnaire design and data collection.

\section{Authors' contributions}

All authors were involved in preparing this manuscript and have provided significant intellectual input. All authors read and approved the final manuscript.

\section{Funding}

This research is partially funded by the National Social Science Fund of China (20XGL018).

\section{Availability of data and materials}

The data is available upon request.

\section{Declarations}

\section{Competing interests}

The authors declare no competing interests related to this work.

\section{Author details}

${ }^{1}$ School of Economics and Management, Southwest Petroleum University, Chengdu, China. ${ }^{2}$ School of Public Affairs and Administration, University of Electronic Science and Technology of China, Chengdu, China.

Received: 21 December 2020 Accepted: 29 April 2021

Published online: 15 June 2021

\section{References}

Akiyoshi, M., \& Ono, H. (2008). The diffusion of mobile Internet in Japan. The Information Society, 24(5), 292-303

Barth, A.-K., \& Heimeshoff, U. (2014). Does the growth of mobile markets cause the demise of fixed networks? -Evidence from the European Union. Telecommunications Policy, 38(11), 945-960. https://doi.org/10.1016/j.telpol.2014.03.003

Blank, G., \& Groselj, D. (2014). Dimensions of Internet use: amount, variety, and types. Information, Communication \& Society, 17(4), 417-435. https://doi.org/10.1080/1369118X.2014.889189

Bui, K. V. T. (2002). First-generation college students at a 4-year university: background characteristics, reasons for pursuing higher education, and first-year experiences. College Student Journal, 36(1), 3-11

Cai, Z., Fan, X., \& Du, J. (2017). Gender and attitudes toward technology use: a meta-analysis. Computers \& Education, 105 , 1-13. https://doi.org/10.1016/j.compedu.2016.11.003

Campos-Castillo, C. (2015). Revisiting the first-level digital divide in the United States: gender and race/ethnicity patterns, 2007-2012. Social Science Computer Review, 33(4), 423-439. https://doi.org/10.1177/0894439314547617

Chan, M. (2015). Multimodal connectedness and quality of life: examining the influences of technology adoption and interpersonal communication on well-being across the life span. Journal of Computer-Mediated Communication, 20(1), 3-18. https://doi.org/10.1111/jcc4.12089 
Chen, Y.-F., \& Katz, J. E. (2009). Extending family to school life: college students' use of the mobile phone. International Journal of Human-Computer Studies, 67(2), 179-191. https://doi.org/10.1016/j.ijhcs.2008.09.002

Chi, X., Lin, L., \& Zhang, P. (2016). Internet addiction among college students in China: prevalence and psychosocial correlates. Cyberpsychology, Behavior, and Social Networking, 19(9), 567-573. https://doi.org/10.1089/cyber.2016.0234

Ching, C. C., Basham, J. D., \& Jang, E. (2005). The legacy of the digital divide: gender, socioeconomic status, and early exposure as predictors of full-spectrum technology use among young adults. Urban Education, 40(4), 394-411. https://doi.org/10.1177/0042085905276389

CNNIC. (2021). The 47th China Statistical Report on Internet Development.

Dong, J. Q., \& Zhang, X. (2011). Gender differences in adoption of information systems: new findings from China. Computers in Human Behavior, 27(1), 384-390. https://doi.org/10.1016/j.chb.2010.08.017

Donner, J. (2015). After access: inclusion, development, and a more mobile internet. MIT Press.

Donner, J., Gitau, S., \& Marsden, G. (2011). Exploring mobile-only Internet use: results of a training study in urban South Africa. International Journal of Communication, 5, 574-597

Felisoni, D. D., \& Godoi, A. S. (2018). Cell phone usage and academic performance: an experiment. Computers and Education, 117, 175-187. https://doi.org/10.1016/j.compedu.2017.10.006

Gitau, S., Marsden, G., \& Donner, J. (2010). After access: Challenges facing mobile-only internet users in the developing world. Paper presented at the Proceedings of the 28th International Conference on Human Factors in Computing Systems (CHI 2010), New York.

Greenhow, C., Walker, J. D., \& Kim, S. (2009). Millennial learners and net-savvy teens? Examining internet use among lowincome students. Journal of Computing in Teacher Education, 26(2), 63-68. https://doi.org/10.1080/10402454.2009. 10784634

Guo, Y., \& Chen, P. (2011). Digital divide and social cleavage: case studies of ICT usage among peasants in contemporary China. The China Quarterly, 207, 580-599. https://doi.org/10.1017/S030574101100066X

Hargittai, E. (2010). Digital na(t)ives? Variation in internet skills and uses among members of the "net generation." Sociological Inquiry, 80(1), 92-113. https://doi.org/10.1111/j.1475-682X.2009.00317.x

Hawi, N. S., \& Samaha, M. (2016). To excel or not to excel: strong evidence on the adverse effect of smartphone addiction on academic performance. Computers \& Education, 98, 81-89. https://doi.org/10.1016/j.compedu.2016.03. 007

Helsper, E., Van Deursen, A., \& Eynon, R. (2016). Measuring Types of Internet Use. From Digital Skills to Tangible Outcomes project report.

Huang, R. L., Lu, Z., Liu, J. J., You, Y. M., Pan, Z. Q., Wei, Z., He, Q., \& Wang, Z. Z. (2009). Features and predictors of problematic internet use in Chinese college students. Behaviour \& Information Technology, 28(5), 485-490. https://doi. org/10.1080/01449290701485801

Humphreys, L., Von Pape, T., \& Karnowski, V. (2013). Evolving mobile media: uses and conceptualizations of the mobile internet. Journal of Computer-Mediated Communication, 18(4), 491-507. https://doi.org/10.1111/jcc4.12019

Janković, B., Nikolić, M., Vukonjanski, J., \& Terek, E. (2016). The impact of Facebook and smart phone usage on the leisure activities and college adjustment of students in Serbia. Computers in Human Behavior, 55, 354-363. https://doi.org/ 10.1016/j.chb.2015.09.022

Junco, R., Merson, D., \& Salter, D. W. (2010). The effect of gender, ethnicity, and income on college students' use of communication technologies. Cyberpsychology, Behavior, and Social Networking, 13(6), 619-627. https://doi.org/10.1089/ cyber.2009.0357

Jung, J. Y. (2008). Where do you go online? A comparison of internet connectedness via personal computers and mobile phones in Japan. International Journal of Mobile Communications, 7(1), 21-35. https://doi.org/10.1504/JJMC.2009. 021670

Kongaut, C., \& Bohlin, E. (2016). Investigating mobile broadband adoption and usage: a case of smartphones in Sweden. Telematics and Informatics, 33(3), 742-752. https://doi.org/10.1016/j.tele.2015.12.002

Kreutzer, T. (2009). Internet and online media usage on mobile phones among low-income urban youth in Cape Town. International Journal of Education and Development using ICT, 5(5), 1-21

Lee, H., Ahn, H., Nguyen, T. G., Choi, S.-W., \& Kim, D. J. (2017). Comparing the self-report and measured smartphone usage of college students: a pilot study. Psychiatry investigation, 14(2), 198-204. https://doi.org/10.4306/pi.2017.14.2.198

Lee, J., \& Kim, J. (2014). Socio-demographic gaps in mobile use, causes, and consequences: a multi-group analysis of the mobile divide model. Information, Communication \& Society, 17(8), 917-936. https://doi.org/10.1080/1369118X.2013. 860182

Lepp, A., Barkley, J. E., \& Karpinski, A. C. (2014). The relationship between cell phone use, academic performance, anxiety, and Satisfaction with Life in college students. Computers in Human Behavior, 31, 343-350. https://doi.org/10.1016/j. chb.2013.10.049

Lepp, A., Barkley, J. E., \& Karpinski, A. C. (2015). The relationship between cell phone use and academic performance in a sample of U.S. college students. SAGE Open, 5(1), 2158244015573169. https://doi.org/10.1177/2158244015573169

Lin, W.-Y., Zhang, X., Jung, J.-Y., \& Kim, Y.-C. (2013). From the wired to wireless generation? Investigating teens' Internet use through the mobile phone. Telecommunications Policy, 37(8), 651-661. https://doi.org/10.1016/j.telpol.2012.09.008

Livingstone, S., \& Helsper, E. (2007). Gradations in digital inclusion: children, young people and the digital divide. New Media \& Society, 9(4), 671-696. https://doi.org/10.1177/1461444807080335

Mossberger, K., Tolbert, C. J., \& Hamilton, A. (2012). Measuring digital citizenship: mobile access and broadband. International Journal of Communication, 6, 2492-2528

Napoli, P. M., \& Obar, J. A. (2014). The emerging mobile internet underclass: a critique of mobile internet access. The Information Society, 30(5), 323-334. https://doi.org/10.1080/01972243.2014.944726

$\mathrm{Ni}$, X., Yan, H., Chen, S., \& Liu, Z. (2009). Factors influencing internet addiction in a sample of freshmen university students in China. CyberPsychology \& Behavior, 12(3), 327-330. https://doi.org/10.1089/cpb.2008.0321

Nielsen, P., \& Fjuk, A. (2010). The reality beyond the hype: mobile internet is primarily an extension of PC-based internet. The Information Society, 26(5), 375-382. https://doi.org/10.1080/01972243.2010.511561 
Pascarella, E. T., Pierson, C. T., Wolniak, G. C., \& Terenzini, P. T. (2004). First-generation college students: additional evidence on college experiences and outcomes. Journal of Higher Education, 75(3), 249-284. https://doi.org/10.1080/00221 546.2004.11772256

Pearce, K. E., \& Rice, R. E. (2013). Digital divides from access to activities: comparing mobile and personal computer internet users. Journal of Communication, 63(4), 721-744

Seo, D. G., Park, Y., Kim, M. K., \& Park, J. (2016). Mobile phone dependency and its impacts on adolescents'social and academic behaviors. Computers in Human Behavior, 63, 282-292. https://doi.org/10.1016/j.chb.2016.05.026

Talukdar, D., \& Gauri, D. (2011). Home internet access and usage in the USA: trends in the socio-economic digital divide. Communications of the Association for Information Systems, 28(1), 85-98. https://doi.org/10.17705/1CAIS.02807

Tsetsi, E., \& Rains, S. A. (2017). Smartphone internet access and use: extending the digital divide and usage gap. Mobile Media \& Communication, 5(3), 239-255. https://doi.org/10.1177/2050157917708329

van Deursen, A., \& van Dijk, J. (2014). The digital divide shifts to differences in usage. New Media \& Society, 16(3), 507-526. https://doi.org/10.1177/1461444813487959

van Deursen, A., van Dijk, J., \& ten Klooster, P. M. (2015). Increasing inequalities in what we do online: a longitudinal cross sectional analysis of Internet activities among the Dutch population (2010 to 2013) over gender, age, education, and income. Telematics and Informatics, 32(2), 259-272. https://doi.org/10.1016/j.tele.2014.09.003

van Deursen, A. J. A. M., Helsper, E. J., \& Eynon, R. (2016). Development and validation of the Internet Skills Scale (ISS). Information, Communication \& Society, 19(6), 804-823. https://doi.org/10.1080/1369118X.2015.1078834

Wang, L., \& Liu, C. (2018). The mobile Internet underclass: reality or hyperbole? Journal of Information Science, 44(5), 569-579. https://doi.org/10.1177/0165551517690083

Wareham, J., Levy, A., \& Shi, W. (2004). Wireless diffusion and mobile computing: implications for the digital divide. Telecommunications Policy, 28(5-6), 439-457. https://doi.org/10.1016/j.telpol.2003.11.005

Wilcockson, T. D. W., Ellis, D. A., \& Shaw, H. (2018). Determining typical smartphone usage: what data do we need? Cyberpsychology, Behavior, and Social Networking, 21(6), 395-398. https://doi.org/10.1089/cyber.2017.0652

Witte, J. C., \& Mannon, S. E. (2010). The Internet and social inequalities. Routledge.

Zillien, N., \& Hargittai, E. (2009). Digital distinction: status-specific types of internet usage. Social Science Quarterly, 90(2), 274-291

\section{Publisher's Note}

Springer Nature remains neutral with regard to jurisdictional claims in published maps and institutional affiliations.

\section{Submit your manuscript to a SpringerOpen ${ }^{\circ}$ journal and benefit from:}

Convenient online submission

- Rigorous peer review

- Open access: articles freely available online

- High visibility within the field

- Retaining the copyright to your article

Submit your next manuscript at $\gg$ springeropen.com 